\title{
Numerical and experimental studies of bent elements of basalt fiber reinforced concrete with prestressed glass composite reinforcement under static and short-term dynamic loads
}

\author{
Vasilii Plevkov ${ }^{1}$, and Konstantin Kudyakov ${ }^{1, *}$ \\ ${ }^{1}$ Tomsk State University of Architecture and Building, Department of Reinforced Concrete and \\ Masonry Structures, 634003, Tomsk, 2 Solyanaya Sq., Russia
}

\begin{abstract}
The article shows studies of bending basalt fiber reinforced concrete elements with pre-stressed glass composite reinforcement under static and short-term dynamic effects. Main results of numerical and experimental studies are presented. It is experimentally established and theoretically confirmed that a significant increase in the strength and crack resistance of the normal sections of concrete bent elements is observed when using basalt fiber reinforcement and pre-stressed glass composite reinforcement.
\end{abstract}

In recent times there has been an increase in the interest of builders in the use of monolithic and prefabricated concrete structures with polymer composite rebars. It is known from the existing studies that the use of combined reinforcement with high-strength rebar and fiber reinforcement has a significant impact on improving the operating properties of concrete structures. The features of concrete structures with combined reinforcement by composite rebar and fiber are poorly understood and are mainly studied for cases of static loading. In particular, few studies currently exist on the option of combined reinforcement with basalt fiber (BF) and pre-stressed glass-composite rebar (GFRP). Studies of such structures survivability under dynamic loads are relevant because of the increasing number of cases of damage and destruction of buildings and structures as a result of explosive effects [1-10].

The study of the features of strain, cracking and failure of bent elements with combined reinforcement with basalt fiber and prestressed glass-composite rebar (BFC-GFRP elements) under short-term dynamic loading was carried out according to the program of experimental studies (Fig. 1). This program included the tests of concrete beams with a span of $2000 \mathrm{~mm}$ and a rectangular cross-section of $100 * 200 \mathrm{~mm}$ under static and shortterm dynamic loads. The pre-stressing level $\sigma_{f p}=0 \ldots 0.45 R_{f}$ and the coefficient of basaltfiber reinforcement $\mu_{b f}=0 \ldots 0.5 \%$ by weight of cement were varied $[11,12]$.

The central part of the beams was reinforced only in the tension region of the cross section with 2 GFRP rods (Ø $6 \mathrm{~mm}$, reinforcement ratio $\left.\mu_{f}=0.28\right)$. The prestressing of GFRP rods was carried out according to the developed technology on a special bench,

\footnotetext{
*Corresponding author: konst_k@mail.ru
} 
which allowed setting the required prestress of the rods and determining its losses. Reinforcement of concrete with BF in the beams was made throughout the whole volume. The composition and manufacturing technology of the basalt-fiber-concrete mixture described in [13-16] were used.

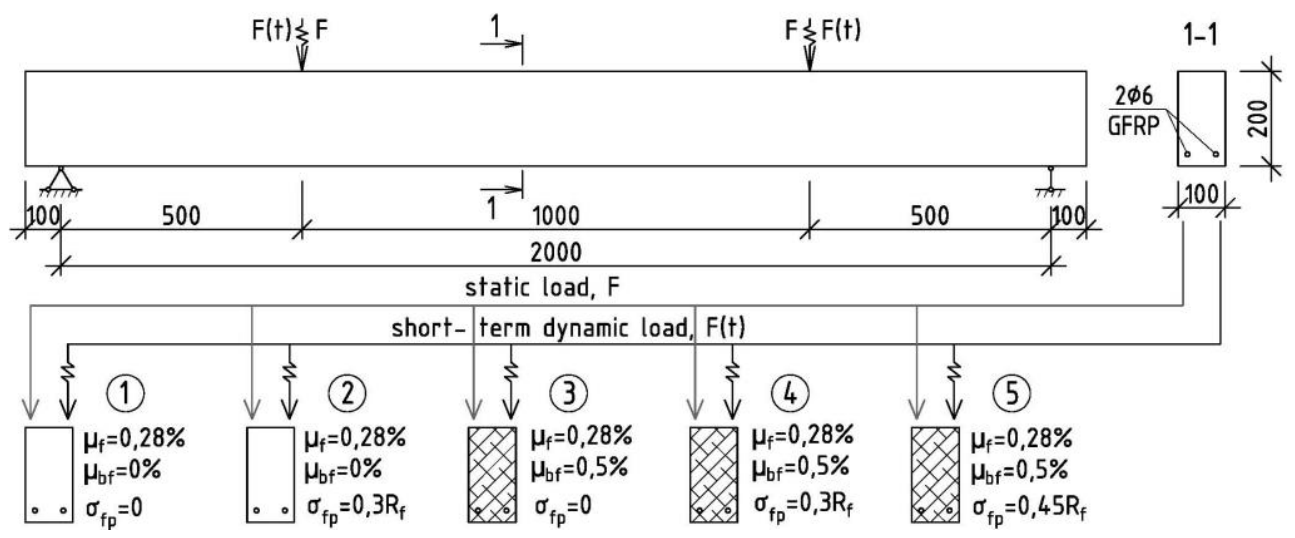

Fig. 1. The program of experimental studies of bent BFC-GFRP elements with static and short-term dynamic loads

To understand the processes occurring in the experimental beams, the mechanical properties of GFRP and basalt fiber reinforced concrete (BFC) were studied. Tension resistance of GFRP to static tension $R_{f}=1280 \mathrm{MPa}$ and modulus of elasticity $E_{f}=60.5 \mathrm{GPa}$ were determined experimentally [17].

BFC studies were conducted depending on the technology and composition. The optimal content (BF reinforcement ratio $\mu_{b f}=0 \ldots 0.5 \%$ by weight of cement) and manufacturing technology for $\mathrm{BFC}$ are determined, at which uniform distribution of basalt fibers in concrete is achieved [14]. Increase in the strength of BFC in compression by $51.2 \%$ and in tension by $28.8 \%$ was obtained, as well as increase in its ultimate strain under compression by $79 \%$ and under tension by $56 \%$ compared to concrete without fiber. Based on the test results, analytical dependencies were proposed for describing the BFC strain under static and short-term dynamic loading [18-19].

Dynamic tests of bent BFC-GFRP elements were carried out on a special bench according to the scheme of a single-span hinge-supported beam. Dynamic loading was created using a freely falling load (Fig. 2, a). Static tests of the beams were carried out according to a similar scheme of support and load application, while loading was created using a hydraulic jack (Fig. 2, b). During the tests, the values of the actual load and the support reactions arising from it, deflection of beams in the middle and quarter of the span, longitudinal strains of the GFRP and BFC along the height of the normal section in the middle of the span of the beams, and the width of the normal cracks opening were measured.

In addition, samples were surveyed using a high-speed camera and a digital optical system for strain measuring VIC-3D, with the help of which the features of strain and cracking arising in the experimental beams were studied, and a qualitative and quantitative assessment of the strain fields of their lateral faces was carried out.

As a result of the static tests of concrete beams $\left(\mu_{b f}=0 \%\right)$ it was found that the prestressing of GFRP by $\sigma_{f p}=0.3 R_{f}$ led to a decrease in deflection values in the middle of the span of bent concrete elements by $42 \%$ and to an increase in the cracking moment up to 3 times in comparison with similar beams without prestressing. 
a)

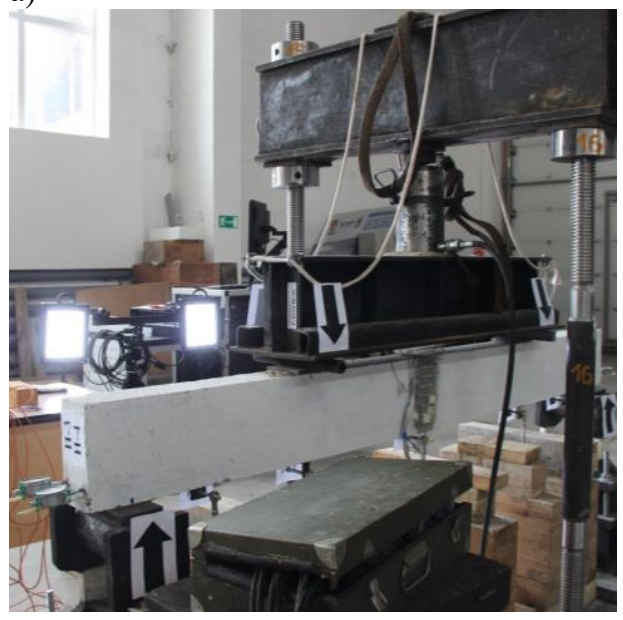

b)

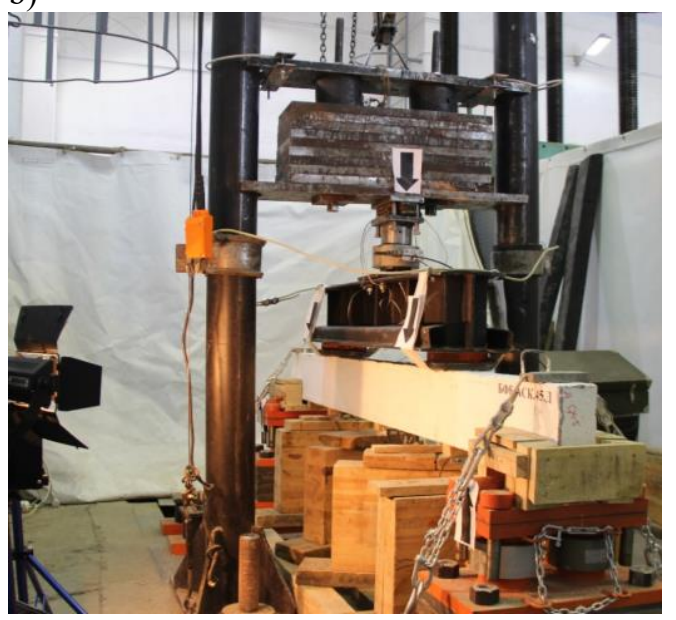

Fig. 2. General views of testing of bent BFC-GFRP elements with static load (a) and short-term dynamic load (b)

Compared to beams without fiber, the basalt-fiber reinforcement of concrete beams $\left(\mu_{b f}=0.5 \%\right)$ with GFRP without prestressing can increase the values of the cracking moment by up to $71 \%$ and the ultimate bending moment by up to $31 \%$; reduce the values of the mid-span deflection by up to $30 \%$ and the crack opening width up to 2 times.

The combined use of basalt-fiber reinforcement $\left(\mu_{b f}=0.5 \%\right)$ and prestressed GFRP $\left(\sigma_{f p}=0.3 R_{f}\right)$ can significantly increase the rigidity and crack resistance of bent BFC-GFRP elements under static loading. At the same time, one can observe increase in the strength of their normal sections by 1.33 times and in the cracking moment by 3.75 times; while the width of the opening of normal cracks reduces up to 2 times in comparison with similar elements without prestressing and fiber reinforcement.

It was experimentally found that the distribution of longitudinal strains of the GFRP and $\mathrm{BFC}$ over the height of the normal section of the beams when increasing the load values has a nearly linear nature. With basalt-fiber reinforcement of compressed and tensed concrete of the beams normal section, an increase in its ultimate strain was found. This allows you to use the strength of the GFRP more effectively.

It was established experimentally that the distribution of longitudinal strain of GFRP and BFC along the height of the normal section of the beams with an increase in the load retains a form that is close to linear. When concrete subjected to compression and tension in the normal section of the beams is reinforced with BF, then its ultimate strains increase. This allows more efficient use of the GFRP.

The strain of bent BFC-GFRP elements under short-term dynamic load was found to have oscillatory nature. Their failure occurring over the normal section had a brittle character and was accompanied by a brief formation of the plastic strain in the BFC compression region of normal sections of elements. Comparison of the results of static and dynamic tests of bent BFC-GFRP elements showed an increase in their strength of normal cross sections under short-term dynamic loading by up to $12.4 \%$, as well as the similarity of the nature of their cracking and failure (Fig. 3). 
a)

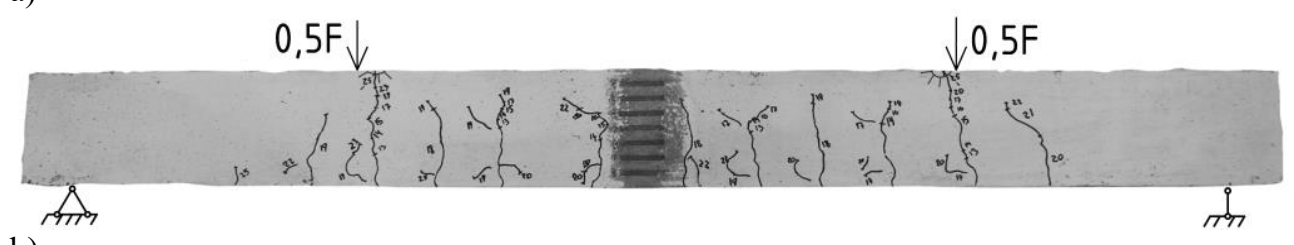

b)

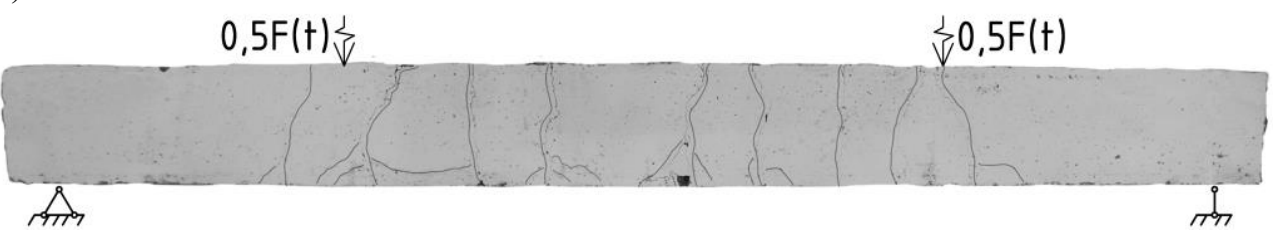

Fig. 3. Typical schemes of crack formation and fracture of bent BFC-GFRP elements under static (a) and short-term dynamic (b) loading

The features of strain of dynamically loaded bent BFC-GFRP elements identified as a result of a physical experiment are similar to the data obtained in [20, 21]. Here, numerical calculations were carried out for finite-element models of experimental structures, which were performed in a three-dimensional shock-wave statement with the use of EFES software (certificate of the Russian state registration of the computer program No. 2011615952). Mathematical models were used in numerical calculations and the actual mechanical parameters of the BFC and GFRP were taken into account. Comparison of the experimental results and calculations showed a qualitative similarity in the schemes of strain, cracking and failure of beams. A quantitative agreement was also obtained between the calculated and experimental values of their displacements and the stresses arising in materials with a difference of $15 \%$.

The effectiveness of BF for concrete reinforcement is shown in the studies [22], where numerical simulation of strain of basalt fiber concrete is considered in comparison with ordinary concrete and steel reinforced concrete under dynamic loading.

Using literary sources and obtained experimental data, the limit states were refined for normal cross sections of bent BFC-GFRP elements under short-term dynamic loading. For calculations on the strength and crack resistance of normal sections of such elements under short-term dynamic loading, it is proposed to consider the following four stages of structural strain, which are limited by the corresponding limit states: 1 - conditionally elastic stage without normal cracks in the tension region of normal section (limit state 1a); 2 - conditionally elastic stage with normal cracks (1a '); 3 - plastic stage (1b); 4 - stage of reducing the bearing capacity (1c).

Verification of the fulfillment of the crack resistance and strength conditions of the normal sections of the bent BFC-GFRP elements can be performed as follows.

The values of internal forces (longitudinal force $N(t)$ and bending moment $M(t)$ ) arising in the structure due to action of an external static or short-term dynamic loads are obtained as a result of analytical or numerical calculation.

These values are compared with the ultimate forces values ( $M_{c r c}$ and $M_{u l t}$, respectively), which are obtained as a result of numerical calculation using BEAM-FRP-BF software developed by the authors (certificate of the Russian state registration of the computer program No. 2011615952)

The basis of this software is a calculation algorithm that implements a non-linear strain model taking into account the dynamic hardening of BFC and GFRP and based on the use of relative resistance surfaces of normal sections of bent BFC-GFRP elements for strength and crack resistance. As a result of the calculation, the ultimate values of the longitudinal 
forces and bending moments are determined, which can be perceived by the normal section of the BFC-GFRP element over the entire period of its operation. These forces are the coordinates that form the boundaries of the surfaces of the resistance of the elements normal section for crack resistance and strength in time, which can be represented in absolute or relative values. The use of relative resistance surfaces makes it possible to visually assess the strength and crack resistance of normal sections of bent BFC-GFRP elements, as well as to determine the ratio of the forces at which the element works with or without normal cracks. At the same time, checking the fulfillment of the conditions of crack resistance and strength is carried out by superimposing the force vectors from external loads onto the corresponding surface of the normal section of elements. The difference between the ultimate values of the forces (the boundary of the resistance surface) and the force vector from the external load are components of the crack resistance or strength reserve, respectively. The developed calculation algorithm also makes it possible to take into account the effect of compression forces from the GFRP prestressing and the value of the fiber reinforcement $\mu_{b f}$ on the crack resistance of the normal section of the bent BFCGFRP element $[12,18,19]$.

More than 70 numerical calculations have been performed for BFC-GFRP beams with the help of this software. The following parameters varied: the value of basalt-fiber reinforcement $\mu_{b f}=0 \ldots 0.5 \%$, the value of core GFRP reinforcement $\mu_{f}=0 \ldots 0.78 \%$, the value of the prestress GFRP $\sigma_{f p}=0 \ldots 0.8 R_{f}$, the position of the GFRP along the height of the normal section. As a result of the calculations, the effect of these parameters on the strength and crack resistance of normal sections of prestressed bent BFC-GFRP elements under short-term dynamic loading was revealed.

Comparison of the experimental data and the results of calculations in the BEAM-FRPBF showed that the calculation method for the non-linear strain model taking into account the actual strain diagrams of materials makes it possible to evaluate the strength and crack resistance of normal sections of bent BFC-GFRP elements with a difference of $\Delta$ within $16.5 \%$ in the direction of the strength reserve. In comparison with the results of calculations of beams under the current Russian regulatory documents, the considered method has the best convergence of the results.

The results of theoretical and experimental studies of bent BFC-GFRP elements allow us to draw the following conclusions:

1. The use of BF and prestressed GFRP reinforcement can significantly reduce the deformability of bent elements under static loading and the width of opening of their normal cracks up to 2 times, and also increase their bearing capacity up to 3.75 times in comparison with concrete elements without BF and prestressing GFRP.

2. It was experimentally found that the strength of normal sections of bent BFC-GFRP elements with short-term dynamic loading in comparison with static loading increased to $12.4 \%$. The strain of such elements under short-term dynamic loading had a pronounced oscillatory nature. Their failure was brittle in nature and was accompanied by a brief formation of BFC plastic strain areas in the compression region of normal sections.

3. The BEAM-FRP-BF software product, which is based on a calculation method and algorithm that implements a non-linear strain model, allows us to solve direct and inverse structural design problems with the high level of accuracy [12].

The study was done with a support of the state assignment of the Ministry of Education and Science of the Russian Federation (project No. 9.6814.2017 / 8.9) and also was funded by RFBR according to the research projects No. 18-48-700035 18 and No. 18-41-703003 $\backslash 18$. 


\section{References}

1. V. Stepanova, A. Stepanov, E. Zhirkov, Polymeric composite rebar (ASV, Moscow, 2013)

2. W. Magdeev, V. Morozov, Yu. Puharenko, A. Hegaj, Academia. Architecture and construction, 2, 106-112 (2016)

3. M. Goldston, A. Remennikov, M. Sheikh, Engineering Structures, 113, 220-232 (2016)

4. M. Tarek, The strength of prestressed bending beam elements, reinforced with fiberglass rebar under the action of short-term dynamic loads, $\mathrm{PhD}$ thesis. (Moscow Civil Engineering Institute of a name Kuibyshev, 1992)

5. T. Pham, H. Hao, International Journal of Protective Structures, 8, 3-24 (2016)

6. O. Kumpiak, D. Kopanitsa, Strength and deformability of reinforced concrete structures under short-term dynamic loading (Northampton, Tomsk, 2002)

7. N. Popov, B. Rastorguev, A. Zabegaev, Calculation of structures for dynamic and special loads (Vysshaya shkola, Moscow, 1992)

8. G. Odnokopilov, D. Sarkisov, Bulletin of the Tomsk Polytechnic University. Geo Assets Engineering, 328, 85-95 (2017)

9. G. Odnokopilov, D. Sarkisov, E. Butuzov, Bulletin of the Tomsk Polytechnic University. Geo Assets Engineering, 339, 122-135 (2018)

10. G. Odnokopilov, O. Kumpyak, Z. Galyautdinov, D. Galyautdinov, Bulletin of the Tomsk Polytechnic University. Geo Assets Engineering, 330, 110-125 (2019)

11. K. Kudyakov, V. Plevkov, A. Nevsky, IOP Conf. Series: Materials Science and Engineering, 71, DOI:10.1088/1757-899X/71/1/012030. (2015)

12. K. Kudyakov, Strength and crack resistance of bending concrete elements with basalt fiber and rod composite reinforcement under static and short-term dynamic loading, $\mathrm{PhD}$ thesis (Tomsk state university of architecture and building, 2018)

13. V. Plevkov, S. Kolupaeva, K. Kudyakov. Vestnik of Tomsk State University of Architecture and Building, 3, 95-110. (2016)

14. A. Kudyakov., V. Plevkov, K. Kudyakov, A. Nevskii, A. Ushakova, Construction Materials, 10, 44-48 (2015)

15. V. Kudyakov, A. Kudyakov, S. Luk'janchikov, K. Kudyakov, Vestnik of Tomsk State University of Architecture and Building, 6, 116-126 (2017)

16. A. Kudyakov, V. Plevkov, K. Kudyakov, A. Nevskii, A. Simakova, V. Efremova, Method for preparation of basalt-fiber-concrete mixture, Patent for invention № 2667402 (2018)

17. V. Plevkov, I. Baldin, K. Kudiakov, A. Nevskii, AIP Conference Proceedings, 1800, DOI 040018-1-040018-5 (2017)

18. O. Kumpyak, Z. Galyautdinov, D. Kokorin, Strength and deformability of reinforced concrete structures on compliant supports under short-term dynamic loads (Izdatel'stvo TGASU, Tomsk, 2016)

19. V. Plevkov, Dynamic strength of concrete and reinforcement of reinforced concrete structures (CNTI, Tomsk, 1996)

20. A. Radchenko, P. Radchenko, Shock-wave processes and destruction in anisotropic materials and structures (Izdatel'stvo TGASU, Tomsk, 2015) 
21. P. Radchenko, S. Batuev, A. Radchenko, V. Plevkov, K. Kudyakov, IOP Conf. Series: Journal of Physics, 774, DOI:10.1088/1742-6596/774/1/012065 (2016)

22. N. Belov, N. Yugov, D. Kopanitsa, V. Plevkov, A. Yugov, V. Shashkov, K. Kudyakov, A. Ustinov, Vestnik of Tomsk State University of Architecture and Building, 46, 63-76 (2014) 